\title{
TRPV1 Is Activated by Both Acidic and Basic pH
}

\author{
Ajay Dhaka, ${ }^{1 *}$ Valerie Uzzell, ${ }^{1 \star}$ Adrienne E. Dubin, ${ }^{1}$ Jayanti Mathur, ${ }^{2}$ Matt Petrus, ${ }^{2}$ Michael Bandell, ${ }^{2}$ and \\ Ardem Patapoutian ${ }^{1,2}$ \\ ${ }^{1}$ Department of Cell Biology, The Scripps Research Institute, La Jolla, California 92037, and ${ }^{2}$ Genomics Institute of the Novartis Research Foundation, San \\ Diego, California 92121
}

\begin{abstract}
Maintaining physiological $\mathrm{pH}$ is required for survival, and exposure to alkaline chemicals such as ammonia (smelling salts) elicits severe pain and inflammation through unknown mechanisms. TRPV1, the capsaicin receptor, is an integrator of noxious stimuli including heat and extracellular acidic $\mathrm{pH}$. Here, we report that ammonia activates TRPV1, TRPA1 (another polymodal nocisensor), and other unknown receptor(s) expressed in sensory neurons. Ammonia and intracellular alkalization activate TRPV1 through a mechanism that involves a cytoplasmic histidine residue, not used by other TRPV1 agonists such as heat, capsaicin or low pH. Our studies show that TRPV1 detects both acidic and basic deviations from homeostatic $\mathrm{pH}$.
\end{abstract}

Key words: TRPA1; TRPV1; ammonia; nociception; alkalization; $\mathrm{pH}$

\section{Introduction}

Ammonia is a noxious volatile chemical and is commonly encountered in household cleansers, artificial fertilizers, industrial pollutants, and in human and animal waste. Exposure to ammonia, which elicits a distinctive pungent sensation in the nose and the airways, can cause mucous membrane irritation and pneumonitis, acutely, and bronchitis, chronically (Flury et al., 1983). Ammonia is also the major component of smelling salts, which can trigger an inhalation reflex and the regaining of consciousness after fainting. Despite the importance and prevalence of ammonia, mechanisms by which ammonia is sensed by the peripheral nervous system are not known.

\section{Materials and Methods}

Mice. All mouse experiments were conducted on mice 6-16 weeks old. TRPA1 knock-out mice have been backcrossed for four generations into the C57BL/6J background (Kwan, 2006). TRPV1 knock-out mice have been backcrossed for $>10$ generations into the C57BL/6J background (Caterina et al., 2000). All experiments were conducted with the approval of The Scripps Research Institute Animal Research Committee.

Ratiometric calcium imaging. Dissociation and culturing of mouse dorsal root ganglia (DRG) neurons was performed as described with the following modifications (Story et al., 2003). Dissected DRGs were dissociated by incubation for $1 \mathrm{~h}$ at $37^{\circ} \mathrm{C}$ in a solution of culture medium (Ham's F12/DMEMwith 10\% Horse Serum, 1\% penicillinstreptomycin) containing $0.125 \%$ collagenase (Worthington Biochemicals) followed by a $30 \mathrm{~min}$ incubation in $10 \mathrm{ml}$ of culture media plus 1.25

Received 0ct. 10, 2008; accepted Nov. 11, 2008.

This work was supported by National Institutes of Health (NIH) Grants R01 NS046303 and NS049104 and the Novartis Research Foundation. A.D. and V.U. are recipients of Ruth L. Kirschstein NIH National Service Research Award Postdoctoral Research Fellowships. We thank T. Earley, M. Garrett, C. Kimball, K. Spencer, and J. Walker for technical help and valuable input.

*A.D. and V.U. contributed equally to this work.

This article is freely available online through the J Neurosci Open Choice option.

Correspondence should be addressed to Prof. Ardem Patapoutian, Department of Cell Biology, The Scripps Research Institute, 10550 North Torrey Pines Road, ICND210F, La Jolla, CA 92037. E-mail: apatapou@gnf.org.

D01:10.1523/JNEUROSCI.4901-08.2009

Copyright $\odot 2009$ Society for Neuroscience $\quad$ 0270-6474/09/290153-06\$15.00/0 units papain. Ca imaging was performed essentially as described previously (Story et al., 2003). Growth media was supplemented with 100 $\mathrm{ng} / \mathrm{ml}$ nerve growth factor. For experiments involving heterologous expression, human embryonic kidney (HEK)293T cells were transiently transfected with rTRPV1 or hTRPA1. The threshold for activation was defined as $80 \%$ above baseline for $\mathrm{NH}_{4} \mathrm{Cl}$ (ammonium chloride) and $40 \%$ above baseline for capsaicin/MO for DRG experiments and $100 \%$ above baseline for capsaicin/MO for heterologous expression experiments. Student's $t$ test was used for all statistical calculations. All averaged traces represent mean \pm SEM.

The buffer solution for all experiments was $1 \times$ Hanks' balanced salt solution (HBSS) (Invitrogen), 10 mм HEPES (Invitrogen), except for studies involving acidic or basic solutions where $1 \times$ HBSS was buffered with $10 \mathrm{~mm}$ Citric acid or $10 \mathrm{~mm}$ TRIS (Sigma), respectively. To determine peak heat/peak capsaicin responses of TRPV1- or TRPV1-H378Qtransfected HEK cells, background heat and capsaicin responses from untransfected HEK cells were subtracted. To determine peak $\mathrm{pH} /$ peak capsaicin of TRPV1- or TRPV1-H378Q-transfected HEK cells, the peak $\mathrm{pH}$ response for each cell was divided by its peak capsaicin response and then averaged, since there was no appreciable background to $\mathrm{pH}$ or capsaicin in untransfected cells.

Fluorescence imaging plate reader. All fluorescence imaging plate reader (FLIPR) experiments were performed essentially as described previously (Macpherson et al., 2006). All responses were normalized by subtracting the response of vector-transfected cells (pcDNA3 alone) and then dividing the background-subtracted response by the peak capsaicin response for the same clone. All data points represent mean \pm SEM. Doseresponse curves were fit using PRISM (GraphPad) software using a nonlinear regression model. These fits were used to compute $\mathrm{EC}_{50} \mathrm{~s}$ for the capsaicin and menthol data. For the $\mathrm{NH}_{4} \mathrm{Cl}$ data, $\mathrm{EC}_{50}$ s were not computed because responses did not clearly saturate at $100 \mathrm{mM} \mathrm{NH}_{4} \mathrm{Cl}$ (the highest concentration which did not elicit major hypertonic responses to $\mathrm{NaCl}$; data not shown). Instead, $\mathrm{NH}_{4} \mathrm{Cl}$ sensitivity was summarized for each WT or mutant clone by computing the peak $\mathrm{NH}_{4} \mathrm{Cl}$ response between 5 and $100 \mathrm{~mm}$ and dividing this response by the response to saturating capsaicin.

Mutagenesis. Site-directed rTRPV1 and TRPA1 mutants were generated by QuikChange II XL Site-Directed Mutagenesis Kit (Stratagene).

Behavior. All behavior analysis was conducted on littermate mice 6-16 
weeks old and was performed blind with respect to genotype. Student's $t$ test was used for all statistical calculations.

Ammonium chloride/capsaicin injections. Mice were acclimated for $20 \mathrm{~min}$ in a transparent Plexiglas box at room temperature. Ten microliters of $375 \mathrm{~mm} \mathrm{NH}_{4} \mathrm{Cl}$ solution was injected subcutaneously into the right hindpaw. This concentration was chosen as the lowest $\mathrm{NH}_{4} \mathrm{Cl}$ concentration which elicited a robust response. For capsaicin control experiments, $10 \mu \mathrm{l}$ of $0.1 \mu \mathrm{g}$ capsaicin was injected. For experiments involving TRPV1 blockers $N$-(4tertiarybutylphenyl)-4-(3-chloropyridin-2yl) tetrahydropyrazine-1 $(2 H)$-carbox-amide (BCTC) or (E)-3-(4-t-butylphenyl)- $N$-(2,3dihydrobenzo $[b][1,4]$ dioxin-6-yl)acrylamide (AMG 9810), animals were injected intraperitoneally $30 \mathrm{~min}$ prior (BCTC) or $15 \mathrm{~min}$ prior (AMG 9810) to $\mathrm{NH}_{4} \mathrm{Cl}$ or capsaicin $(0.1$ $\mu \mathrm{g}$ in $10 \mu \mathrm{l})$ administration with $10 \mathrm{mg} / \mathrm{kg}$ BCTC (Biomol), $30 \mathrm{mg} / \mathrm{kg}$ AMG 9810 (Biomol) or vehicle (45\% hydroypropyl- $\beta$ cyclodextrin; Sigma). The total time spent licking, flicking the injected paw was recorded for $10 \mathrm{~min}$.

Electrophysiology. HEK293T cells transfected with mTRPA1-IRES-YFP or hTRPA1-IRESGFP or cotransfected with rTRPV1 or rTRPV1$\mathrm{H} 378 \mathrm{Q}$ and the IRES-YFP-expressing vector were cultured in the presence of $10 \mu \mathrm{M}$ ruthenium red for $12-18 \mathrm{~h}$ at $37^{\circ} \mathrm{C}$ followed by further incubation at $33^{\circ} \mathrm{C}$ for $1-3 \mathrm{~d}$ before testing. Whole-cell and excised inside-out patch experiments were performed essentially as described previously (Macpherson et al., 2007). Basic EGTA-buffered $0 \mathrm{mM} \mathrm{Ca}^{2+}$ solutions were tested on recombinant channels in the excised patch configuration and results were confirmed in ruptured whole-cell studies with basic and control (neutralized) solutions in the pipette. $\mathrm{NH}_{4} \mathrm{Cl}$ was bath applied to intact cells and TRP channel activity was recorded in cell attached patches. In cell attached or excised patch experiments, the pipette contained $2 \mathrm{~mm} \mathrm{Ca}^{2+} \mathrm{ES}$ and had resistances of 6-20 MOhm when filled. Cells were bathed in high extracellular $\mathrm{K}^{+}\left[2 \mathrm{mM} \mathrm{Ca}^{2+} / \mathrm{HighK}^{+}\right.$-ES; containing (in $\mathrm{mm}$ ): $136 \mathrm{KCl}, 5$ $\mathrm{NaCl}, 2 \mathrm{MgCl}_{2}, 2 \mathrm{CaCl}_{2}, 10$ HEPES, pH 7.3 with $\mathrm{NaOH}$ ] to shift the membrane potential toward $0 \mathrm{mV}$ and avoid voltage-dependent changes in TRP activity due to off target effects on endogenous background currents. The membrane potential is likely to be close to zero since the reversal potentials of $\mathrm{NH}_{4} \mathrm{Cl}$-induced TRPV1 and TRPA1 currents were near zero in the cell-attach patch configuration. Some experiments were performed with $5 \mathrm{~mm} \mathrm{~K}{ }^{+}\left(2 \mathrm{~mm} \mathrm{Ca}^{2+} \mathrm{ES}\right)$ in the bath and results were similar. Cells were continuously perfused with external saline and maintained at $25^{\circ} \mathrm{C}$. TRPV 1 or TRPA 1 channel activity was usually monitored using repetitive voltage ramps (acquired at $5 \mathrm{~s}$ intervals) from a holding potential of $-50 \mathrm{mV}$. The voltage was hyperpolarized briefly before a $2.8 \mathrm{mV} / \mathrm{msec}$ ramp to $+120 \mathrm{mV}$ and then held at $+120 \mathrm{mV}$ for $9 \mathrm{~ms}$ before returning to the holding potential. Occasionally, channel activity was monitored during a step to $+125 \mathrm{mV}$ (supplemental Fig. $3 B$, available at www.jneurosci.org as supplemental material). Only patches containing relatively few channels were chosen for study to obtain blank sweeps during control and activated conditions. Occasionally, while few channels were observed in control conditions, upon activation by agonist the basal level (no TRP channel openings) could not be obtained (see Fig. $2 \mathrm{~B})$. In these cases, antagonist was used to determine the contributing endogenous conductance (that was required for determination of fold change compared with control; see data analysis). The vehicle (DMSO, $0.1 \%$ ) had no effect on channel activity. All data were acquired at 11.1 $\mathrm{kHz}$ and single channel records were filtered off-line at $3 \mathrm{kHz}$.

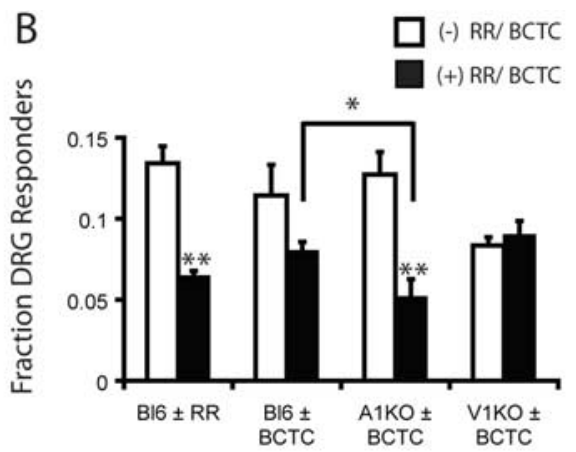

$\mathrm{D}$

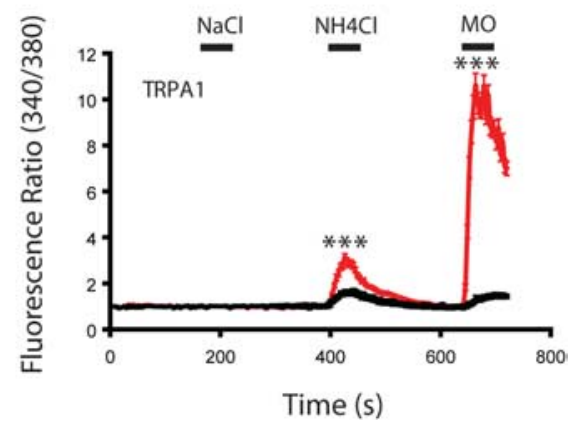

Time (s)

Figure 1. TRPV1 and TRPA1 are activated by $\mathrm{NH}_{4} \mathrm{Cl}$. Responses of dissociated DRG neurons and transfected HEK cells were from Bl6 $\left[n=5(\mathrm{RR}) ; n=4\right.$ (BCTC)], TRPA1 ${ }^{-1-}(n=5)$ or TRPV1 ${ }^{-1-}(n=3)$ animals responding to $\mathrm{NH}_{4} \mathrm{Cl}(50 \mathrm{~mm})$ in the expressing HEK cells (red) do not respond to $10 \mathrm{M}$ ). Approximately 300 neurons/COndion/animal were analyzed. $C$, TRPV1oil $(100 \mu \mathrm{M})$. Untransfected HEK cells (black). Caps, Capsaicin; RR, ruthenium red. ${ }^{*} p<0.05,{ }^{* *} p<0.005,{ }^{* * *} p<0.001$.

Analysis of fold change in channel activity. Stimuli-induced changes in TRP activity compared with control levels were determined. Blank sweeps were observed to contain no TRP openings in the absence or presence of agonist and were used to determine the "leak"-subtracted control and agonist-induced level of activity at $+120 \mathrm{mV}$. The fold change in activity was calculated by measuring the TRP-mediated current at $+120 \mathrm{mV}$ obtained by averaging consecutive traces acquired $1-2$ min before agonist addition and during the maximal effect of agonist. Patch currents were stable ( $<5 \%$ change in basal current) throughout the measurements. $\mathrm{NH}_{4} \mathrm{Cl}(100 \mathrm{~mm})$ occasionally increased a small endogenous conductance that was distinguishable from TRP channel activity based on its smooth characteristics, long latency and insensitivity to BCTC or AP18 (data not shown). Data in all figures and text are shown as mean \pm SEM. Statistical significance between groups was evaluated using Student's $t$ test; the one-sample $t$ test was used to determine whether a fold change was different from 1.

\section{Results}

$\mathrm{NH}_{4} \mathrm{Cl}$ has been shown to elicit robust responses in cultured DRG neurons (Mironov and Lux, 1991; Pidoplichko, 1992). Furthermore, it is well established that exposure to external $\mathrm{NH}_{4} \mathrm{Cl}$ solutions, through the diffusion of free $\mathrm{NH}_{3}$ (ammonia) across the plasma membrane, leads to the internal alkalization of many cell types including DRG neurons (Mironov and Lux, 1991; Pidoplichko, 1992; Yodozawa et al., 1997; Kiss and Korn, 1999). DRG neurons are specialized to sense various chemical and physical stimuli in tissues such as the skin and internal organs (Dhaka et al., 2006). Using calcium imaging, we observed that $\sim 13 \%$ of cultured DRG neurons responded to $50 \mathrm{mM} \mathrm{NH}_{4} \mathrm{Cl}$, correspond- 
A
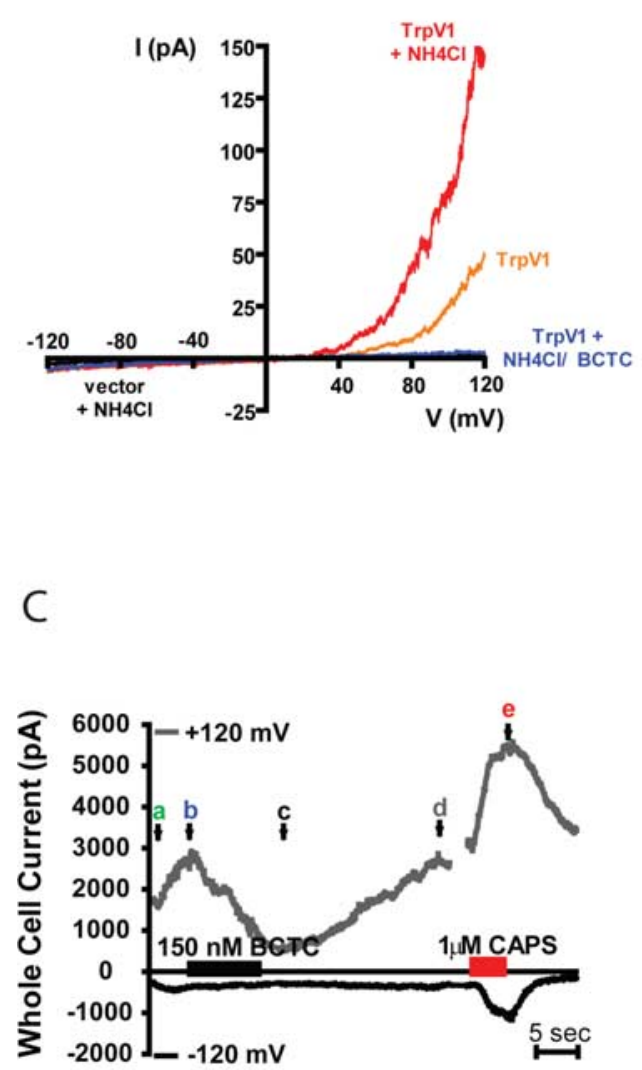

B
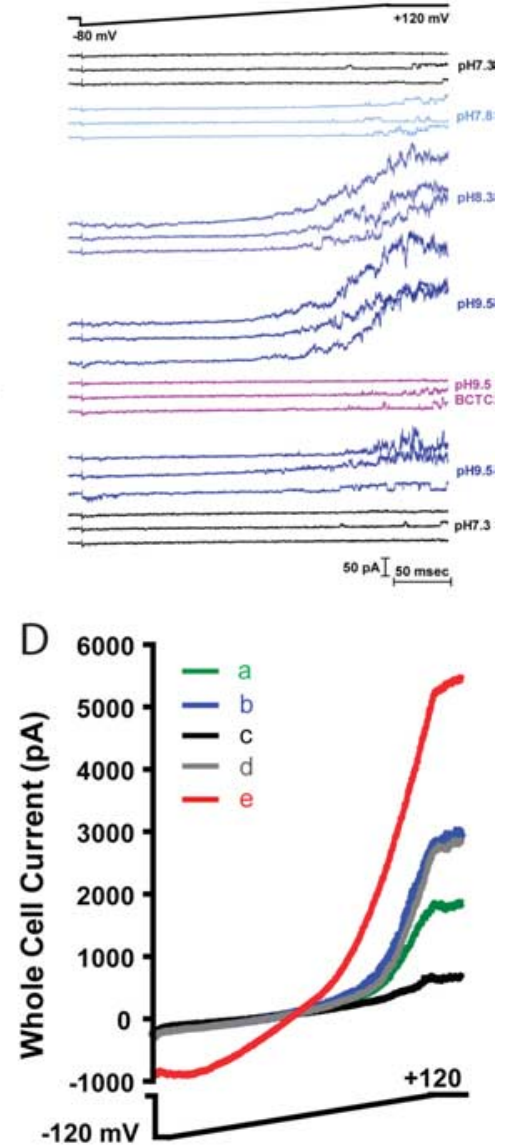

Figure 2. TRPV1 is activated by intracellular alkalization. $\boldsymbol{A}, \mathrm{NH}_{4} \mathrm{Cl}(50 \mathrm{~mm})$ increases channel activity recorded in a cellattached patch from TRPV1-expressing HEK cells (fold change, $4.1 \pm 0.8, n=5$ ) in a BCTC-sensitive manner. Membrane patches were challenged with a voltage ramp protocol $\left(\boldsymbol{B} ; 0.25 \mathrm{~Hz}\right.$ ), and cells were maintained in high extracellular $\mathrm{K}^{+}$(see supplemental methods). The response onset to $\mathrm{NH}_{4} \mathrm{Cl}$ was rapid $(20 \pm 3 \mathrm{~s} ; n=5)$. Thirty consecutive sweeps were averaged before (orange) and after (red) activation by $\mathrm{NH}_{4} \mathrm{Cl}$. BCTC ( $300 \mathrm{~nm}$ ) inhibited the activation of channel activity by $\mathrm{NH}_{4} \mathrm{Cl}$ when cells were preincubated in BCTC (blue trace is a typical example). Vector transfected cells revealed little/no effect of $50 \mathrm{~mm} \mathrm{NH}_{4} \mathrm{Cl}$ (black). $\boldsymbol{B}, \mathrm{pH}$ and BCTC dependence of TRPV1 activity in excised inside-out membrane patch. TRPV1 activity is observed at positive potentials in control conditions (pH 7.3, $25^{\circ} \mathrm{C}$; black). Subsequent bath application of pH 7.8 (light blue traces), pH 8.3 (blue) and pH 9.5 (dark blue) increased channel activity at $+120 \mathrm{mV}$ by $5-, 40$ - and 45 -fold, respectively. The latency to TRPV1 activation by $\mathrm{pH} 7.8$ and pH 8.3 was $50 \pm 13 \mathrm{~s}(n=5)$ and $18 \pm 2 \mathrm{~s}(n=8)$. The TRPV1 antagonist BCTC ( $300 \mathrm{~nm})$ nearly abolished the activity in the $\mathrm{pH} 9.5$ solution (pink), and block was partially reversible upon washout of the antagonist at pH 9.5 (dark blue). The effect of base on TRPV1 was reversed completely upon return to control pH 7.3 solution (black). Representative traces are shown (every $16-20 \mathrm{~s}$ ) during the peak of each effect. $\boldsymbol{C}, \boldsymbol{D}$, Whole-cell conductance was monitored from a cell expressing rat TRPV1 at $0.2 \mathrm{~Hz}$ over $\sim 50$ min after achieving the whole-cell configuration with a pipette containing $\mathrm{pH} 8.3$ (pipette resistance, $1.7 \mathrm{MOhm}$; voltage protocol in 2D). Voltage ramp-induced currents were acquired every 5 s from a holding potential of $-50 \mathrm{mV}$. The membrane potential was stepped to $-120 \mathrm{mV}$, ramped to $+120 \mathrm{mV}$ at a speed of $2.85 \mathrm{mV} / \mathrm{ms}$ and maintained at $+120 \mathrm{mV}$ for $50 \mathrm{~ms}$. Outwardly rectifying currents (control a shown in green in $\boldsymbol{D}$ ) were measured at $+120 \mathrm{mV}$ and $-120 \mathrm{mV}$ and the time course plotted $(\boldsymbol{C}$ ). After a couple of minutes (data not shown, see below), outwardly rectifying currents increased (b indicated in $\boldsymbol{C}$, blue trace in $\boldsymbol{D}$ ) and were reversibly blocked by bath application of $150 \mathrm{~nm}$ BCTC (c indicated in $\boldsymbol{C}$, black trace in $\boldsymbol{D}$ ). After washout ( $\mathrm{d}$ in $\boldsymbol{C}$, gray trace in D), capsaicin (CAPS, $1 \mathrm{~mm}$ ) was bath applied and elicited large outwardly rectifying currents with substantial inward current (e in $\boldsymbol{C}$, red trace in $\boldsymbol{D}$ ) which reversed upon washout. Upon patch rupture, a transient increase in conductance was observed (data not shown) that was dependent on rTRPV1 expression and was independent of the pH used to backfill the pipette since it was also observed in cells with pipettes filled with neutralized IS or standard IS.

ing to an internal $\mathrm{pH} \geq 8.0$ (Mironov and Lux, 1991), and the vast majority of these neurons $(\sim 80 \%)$ also responded to the TRPV1 agonist capsaicin (Fig. $1 \mathrm{~A}$; supplemental Fig. $1 \mathrm{~A}$, supplemental Table 1, available at www.jneurosci.org as supplemental material). Interestingly, a $50 \mathrm{~mm}$ solution of $\mathrm{NH}_{4} \mathrm{Cl}\left(\mathrm{pH} 7.2-7.4,25^{\circ} \mathrm{C}\right)$ contains $\sim 0.5 \mathrm{~mm}$ free ammonia, whereas household cleansers typically contain $5-10 \%$ ammonia $(2.6-5.26 \mathrm{M})$, suggesting that DRG neurons could be activated by concentrations of ammonia encountered in the real world (Pidoplichko, 1992). Equimolar concentrations of up to $100 \mathrm{mM} \mathrm{NaCl}$ did not elicit responses in these neurons, ruling out hyperosmolarity as the cause of calcium influx (Fig. 1A) (Ciura and Bourque, 2006). Furthermore, the $\mathrm{NH}_{4} \mathrm{Cl}$ response required extracellular calcium, indicating the involvement of one or more cation channel(s) (supplemental Fig. $1 B$, available at www.jneurosci. org as supplemental material). Ruthenium Red (RR), a known blocker of TRPV1 and TRPA1, another polymodal nociceptor localized within the TRPV1-expressing neurons, significantly reduced but did not eliminate the number of neurons sensitive to ammonia [wildtype (WT) Bl6 (13 \pm $1 \%)$; WT Bl6+RR $(6 \pm 0.3 \%) ; p<0.005)]$ (Fig. $1 B$; supplemental Fig. $1 C-D$, supplemental Table 2, available at www.jneurosci. org as supplemental material) (Dhaka et al., 2006). This suggests that TRPV1 and/or TRPA1 could play a role in the ammonia response, in addition to other RRinsensitive ion channel(s).

Strikingly, concentrations of $\mathrm{NH}_{4} \mathrm{Cl}$ that activate DRGs elicited a strong influx of calcium in TRPV1-expressing HEK cells, while $\mathrm{NaCl}$ had no effect (Fig. 1C). To further characterize $\mathrm{NH}_{4} \mathrm{Cl}$-induced responses, we recorded TRPV1 channel activity in cell-attached patches during exposure to $\mathrm{NH}_{4} \mathrm{Cl}$, and observed rapidly activating and outwardly rectifying currents not observed in vector-transfected cells (Fig. 2A). These currents were blocked by the TRPV1 antagonist $\mathrm{N}$-(4tertiarybutylphenyl)-4-(3-chloropyridin2 -yl) tetrahydropyrazine $-1(2 H)$-carboxamide (BCTC) (Fig. $2 A$; supplemental Fig. $3 A$, available at www.jneurosci.org as supplemental material) (Valenzano et al., 2003). Since ammonia could act on either extracellular or intracellular residues of TRPV1, we asked whether the application of extracellular or intracellular $\mathrm{pH}$ was sufficient to activate TRPV1. Extracellular $\mathrm{pH}$ 9.0 was unable to activate TRPV1-expressing HEK cells (supplemental Fig. $2 \mathrm{~A}$, available at www.jneurosci.org as supplemental material). However, the application of alkaline solutions ranging from $\mathrm{pH} 7.8-$ 9.5 increasingly activated TRPV1 channels in inside-out patches as well as in whole-cell configuration, and this activation was reversibly blocked by BCTC (Fig. $2 B-D$ ) (data not shown). This indicates that intracellular alkalization is sufficient to activate TRPV1. Therefore, TRPV1 is activated by both acidic (extracellular) and basic (intracellular) $\mathrm{pH}$ (Tominaga et al., 1998).

Since RR blocked DRG responses to $\mathrm{NH}_{4} \mathrm{Cl}$ and TRPAl is another target of RR, we investigated whether TRPAl could also be activated by $\mathrm{NH}_{4} \mathrm{Cl}$. TRPA1-expressing HEK293 cells were 
submaximally activated by $\mathrm{NH}_{4} \mathrm{Cl}$ when compared with activation by the TRPA1 agonist mustard oil, but not by $\mathrm{NaCl}$ or extracellular $\mathrm{pH}$ 9.0, indicating that internal alkalization may be the mechanism by which $\mathrm{NH}_{4} \mathrm{Cl}$ activates TRPA1 (Fig. $1 D$; supplemental Figs. $2 B, 3 B$, available at www.jneurosci.org as supplemental material). Indeed, alkaline $\mathrm{pH}$ activated TRPA1 in inside-out patches and in whole-cell configuration, although robust activation required a higher $\mathrm{pH}$ (9.5) than was required for TRPV1, pH 7.8 (supplemental Fig. $3 C-D$, available at www.jneurosci.org as supplemental material) (data not shown). This indicates that TRPV1 is more sensitive to internal basic solutions than TRPA1, at least in heterologous expression conditions. Other thermoTRPs, TRPV2-4 and TRPM8, were not activated by $100 \mathrm{mM}$ $\mathrm{NH}_{4} \mathrm{Cl}$ (data not shown).

Although TRPV1 is more potently activated than TRPA1 by $\mathrm{NH}_{4} \mathrm{Cl}$ in heterologous expression conditions, it is still possible that TRPV1 and/or TRPA1 could play a role in the ability of DRG neurons to respond to $\mathrm{NH}_{4} \mathrm{Cl}$. To determine if these ion channels play a role in $\mathrm{NH}_{4} \mathrm{Cl}$ responses in sensory neurons, we calculated the fraction of DRG neurons responding to $\mathrm{NH}_{4} \mathrm{Cl}$ in WT Bl6, TRPV1 ${ }^{-/-}$, or TRPA1 $1^{-/-}$mice. Neither TRPV1 ${ }^{-/-}$nor TRPA ${ }^{-/-}$mice had a significant reduction in the number of DRG neurons activated by $\mathrm{NH}_{4} \mathrm{Cl}$ (supplemental Table 1, available at www.jneurosci.org as supplemental material). This raises the possibility that TRPV1 and TRPA1 compensate for each other. To test this, we pharmacologically blocked TRPV1 with BCTC in TRPA1 ${ }^{-/-}$DRG neurons. Consistent with this model, we observed a significant reduction in the fraction of neurons responding to $\mathrm{NH}_{4} \mathrm{Cl}$ with BCTC (13 $\pm 1 \%$ to $5 \pm 1 \%, p<0.005$ ) (Fig. $1 B$; supplemental Fig. $4 A, B$, supplemental Table 2, available at www.jneurosci.org as supplemental material). BCTC applied to WT Bl6 neurons caused some reduction in $\mathrm{NH}_{4} \mathrm{Cl}$ responses; however, statistical significance was not achieved (Fig. $1 \mathrm{~B}$, supplemental Table 2, available at www.jneurosci.org as supplemental material). We did not observe a reduction in $\mathrm{NH}_{4} \mathrm{Cl}$-activated cells in TRPV1 ${ }^{-/-}$DRG neurons treated with BCTC, demonstrating the specificity of BCTC (Fig. 1 B; supplemental Table 2, available at www.jneurosci.org as supplemental material). It appears then that within DRG neurons, TRPV1 and TRPA1 have redundant roles in mediating responses to $\mathrm{NH}_{4} \mathrm{Cl}$.

A significant number of neurons still responded to $\mathrm{NH}_{4} \mathrm{Cl}$ in BCTC-treated TRPA1 ${ }^{-1-}$ DRG neurons, analogous to the RR effects on WT Bl6 neurons $(6 \pm 0.3 \% \mathrm{Bl} 6+\mathrm{RR}, 5 \pm 1 \%$ TRPA1 ${ }^{-1-}+$ BCTC). This suggests the existence of an as yet uncharacterized receptor(s) for ammonia. Consistent with this, we were unable to observe significant reductions in the nocicep-
B

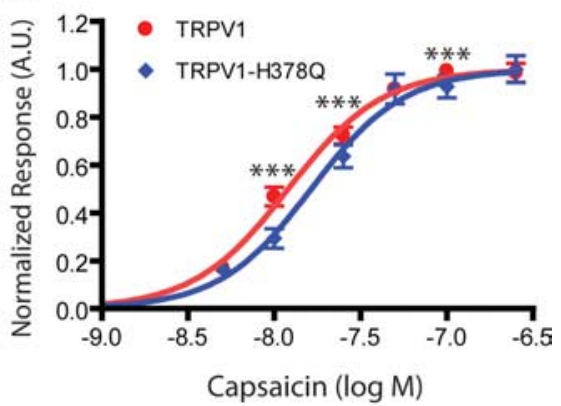

D

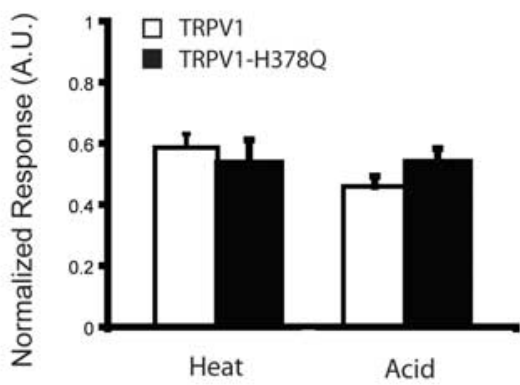

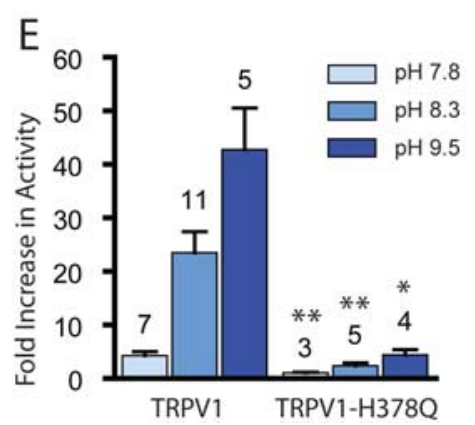

Figure 3. Activation of TRPV1 by $\mathrm{NH}_{4} \mathrm{Cl}$ or intracellular basic $\mathrm{pH}$ is dependent on a single histidine residue $\mathrm{H} 378$. $\mathrm{A}$, The mutant TRPV1-H3780 does not respond to $\mathrm{NH}_{4} \mathrm{Cl}$. FLIPR dose responses to $\mathrm{NH}_{4} \mathrm{Cl}$, normalized to peak capsaicin response, are shown for WT TRPV1 and TRPV1-H378Q. B, TRPV1-H378Q shows minor differences in the capsaicin dose-response. FLIPR dose responses, normalized to peak capsaicin response, are shown for TRPV1 ( $\mathrm{EC}_{50} 12 \mathrm{~nm} \pm 0.7 \mathrm{~nm}$ ) and TRPV1-H378Q ( $\left.\mathrm{EC}_{50} 16 \pm 1 \mathrm{~nm}\right) . C$ 列 Whole-cell current density elicited by 5, 10, 30 and $300 \mathrm{~nm}$ capsaicin are shown for TRPV1 (blue; $\mathrm{EC}_{50} 41 \pm 10 \mathrm{~nm}$ ) and TRPV1(red; $\mathrm{EC}_{50} 33 \pm 16 \mathrm{~nm}$ ) (3-7 data points per concentration). D, TRPV1-H378Q responds normally to heat and acid. Peak TRPV1 or TRPV1-H3780, using ratiometric calcium imaging. $\boldsymbol{E}$, TRPV1-H378Q is severely impaired in its response to alkaline $\mathrm{pH}$. was applied to the cytoplasmic side of excised inside-out membranes and average channel activity was measured at $+120 \mathrm{mV}$ in the absence and presence of basic solutions at the indicated pH. The fold increases in activity for TRPV1 and TRPV1-H378Q are significantly different for all basic solutions. ${ }^{*} p<0.05,{ }^{* *} p<0.005,{ }^{* * *} p<0.001$. a.u., Arbitrary unit.

tive $\mathrm{NH}_{4} \mathrm{Cl}$ response in TRPV1 ${ }^{-/-}$mice, TRPA1 $1^{-/-}$mice, or TRPA1 $1^{-/-}$mice treated with BCTC or another TRPV1 antagonist AMG 9810 when compared with controls (supplemental Fig. 5, available at www.jneurosci.org as supplemental material) (Gavva et al., 2005). The lack of behavioral phenotype might reflect the fact that ammonia acts on multiple target receptors, and this promiscuity might explain the overwhelming sensory quality of ammonia. Interestingly, various ion channels (N-type calcium channels, HCN2, CatSper1) are known to be activated or modulated by intracellular alkalization; however, whether these ion channels are sensors of ammonia in sensory neurons has not been investigated (Kiss and Korn, 1999; Zong et al., 2001; Kirichok et al., 2006).

We next investigated which residues might be involved in the 


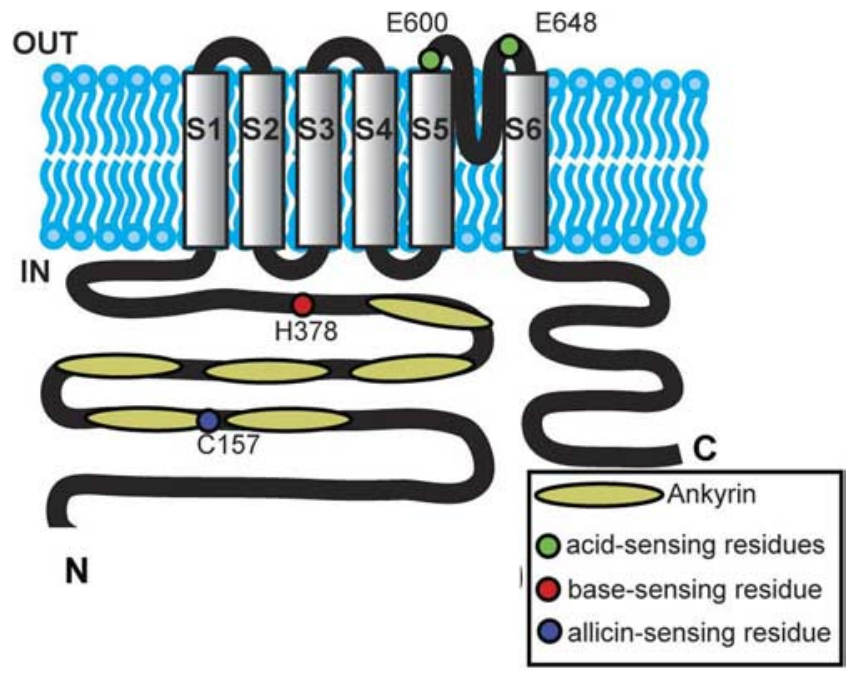

Figure 4. Diagram representation of TRPV1 showing acid (Tominaga et al., 1998), base and allicin-sensing residues (Salazar et al., 2008).

activation of TRPA1 and TRPV1 by intracellular alkalization. We focused our search on cysteine and histidine residues because they have average pKa values, 8.4 and 6.0, respectively, closest to physiological $\mathrm{pH}$ and therefore could be targets for alkaline deprotonation (Padanilam et al., 2002). Since TRPA1 is known to be activated by cysteine modifications (Hinman et al., 2006; Macpherson et al., 2007), we assessed whether three previously characterized intracellular TRPA1 cysteine mutants (defective in their response to reactive chemicals) (Hinman et al., 2006) are required for responses to $\mathrm{NH}_{4} \mathrm{Cl}$ as well as menthol, a nonreactive control TRPA1 activator (Xiao et al., 2008). Two mutants showed either complete (C621S) or partial (C665S) loss of ammonia activation while retaining normal menthol sensitivity, used here to access overall channel functionality (supplemental Fig. 6A-C, available at www.jneurosci.org as supplemental material). These data suggest that ammonia activates TRPA1 through modification of previously characterized intracellular cysteine residues.

To understand how alkaline $\mathrm{pH}$ activates TRPV1, we first investigated an intracellular cysteine residue (C157) previously shown to be required for the activation of TRPV1 by reactive compounds (Salazar et al., 2008). Mutation of this residue (TRPV1-C157A) caused no impairment in the response to $\mathrm{NH}_{4} \mathrm{Cl}$ relative to wild-type TRPV1 (data not shown). We next mutated all 12 TRPV1 histidine residues individually to glutamine or arginine and characterized their dose-response to $\mathrm{NH}_{4} \mathrm{Cl}$ and capsaicin using FLIPR (supplemental Fig. 7A-C, available at www.jneurosci.org as supplemental material). Remarkably, a single intracellular histidine residue (H378), located between the last ankyrin repeat domain and the first transmembrane domain (no crystal structural information is available for this region) (Lishko et al., 2007), was specifically required for $\mathrm{NH}_{4} \mathrm{Cl}$ sensitivity while only having a small but significant effect on capsaicin responses (Fig. $3 A, B$ ). However, using whole-cell voltage-clamp recordings, we observed no significant differences in the capsaicin concentration dependence between TRPV1H378Q and TRPV1 (Fig. 3C). TRPV1-H378Q also showed normal activation by heat (heat $\left.\operatorname{ramp} 25-48^{\circ} \mathrm{C}\right)$ and acidic $\mathrm{pH}(\mathrm{pH}$ 4.5-5) (Fig. 3D). Importantly, TRPV1-H378Q, in inside-out patches, was severely impaired in its responses to alkaline $\mathrm{pH}$ (Fig. $3 E$ ). Internal alkalization therefore activates TRPV1 via a novel site (Fig. 4) that is not required for normal heat, capsaicin or extracellular acid activation and this activity requires a single cytoplasmic histidine residue.

\section{Discussion}

TRPV1 and TRPA1 are remarkable in their ability to sense a wide range of noxious stimuli. Here, we have provided conclusive evidence that both TRPV1 and TRPA1 directly sense ammonia and intracellular base. TRPA1 responses to ammonia and intracellular base are mediated by a known mechanism involving cysteine modification. In contrast, we have identified a novel and distinct means of TRPV1 activation by ammonia and base that depends on a single intracellular histidine residue. Mechanistically, how intracellular high pH activates TRPV1 (or TRPA1) is not known; however, the most parsimonious explanation is that deprotonation of H378 (and potentially other residues) of TRPV1 cause novel intra or intermolecular interactions within the channel leading to conformational changes and ultimately channel gating. To our knowledge, TRPV1 is the first identified ion channel which has the striking ability to be activated by both acidic and alkaline $\mathrm{pH}$.

Note added in proof. Another study has recently reported the activation of TRPA1 by ammonia (Fujita et al., 2008).

\section{References}

Caterina MJ, Leffler A, Malmberg AB, Martin WJ, Trafton J, Petersen-Zeitz KR, Koltzenburg M, Basbaum AI, Julius D (2000) Impaired nociception and pain sensation in mice lacking the capsaicin receptor. Science 288 : $306-313$.

Ciura S, Bourque CW (2006) Transient receptor potential vanilloid 1 is required for intrinsic osmoreception in organum vasculosum lamina terminalis neurons and for normal thirst responses to systemic hyperosmolality. J Neurosci 26:9069-9075.

Dhaka A, Viswanath V, Patapoutian A (2006) TRP ion channels and temperature sensation. Annu Rev Neurosci 29:135-161.

Flury KE, Dines DE, Rodarte JR, Rodgers R (1983) Airway obstruction due to inhalation of ammonia. Mayo Clin Proc 58:389-393.

Fujita F, Uchida K, Moriyama T, Shima A, Shibasaki K, Inada H, Sokabe T, Tominaga M (2008) Intracellular alkalization causes pain sensation through activation of TRPA1 in mice. J Clin Invest 118:4049-4057.

Gavva NR, Tamir R, Qu Y, Klionsky L, Zhang TJ, Immke D, Wang J, Zhu D, Vanderah TW, Porreca F, Doherty EM, Norman MH, Wild KD, Bannon AW, Louis JC, Treanor JJ (2005) AMG 9810 [(E)-3-(4-t-butylphenyl)$N$-(2,3-dihydrobenzo[b] [1,4] dioxin-6-yl)acrylamide], a novel vanilloid receptor 1 (TRPV1) antagonist with antihyperalgesic properties. J Pharmacol Exp Ther 313:474-484.

Hinman A, Chuang HH, Bautista DM, Julius D (2006) TRP channel activation by reversible covalent modification. Proc Natl Acad Sci U S A 103:19564-19568.

Kirichok Y, Navarro B, Clapham DE (2006) Whole-cell patch-clamp measurements of spermatozoa reveal an alkaline-activated $\mathrm{Ca} 2+$ channel. Nature 439:737-740.

Kiss L, Korn SJ (1999) Modulation of N-type Ca2 + channels by intracellular $\mathrm{pH}$ in chick sensory neurons. J Neurophysiol 81:1839-1847.

Kwan KY, Allchorne AJ, Vollrath MA, Christensen AP, Zhang DS, Wolf CJ, Corey DP (2006) TRPAl contributes to cold, mechanical, and chemical nociception but is not essential for hair-cell transduction. Neuron 50: 277-289.

Lishko PV, Procko E, Jin X, Phelps CB, Gaudet R (2007) The ankyrin repeats of TRPV1 bind multiple ligands and modulate channel sensitivity. Neuron 54:905-918.

Macpherson LJ, Hwang SW, Miyamoto T, Dubin AE, Patapoutian A, Story GM (2006) More than cool: promiscuous relationships of menthol and other sensory compounds. Mol Cell Neurosci 32:335-343.

Macpherson LJ, Dubin AE, Evans MJ, Marr F, Schultz PG, Cravatt BF, Patapoutian A (2007) Noxious compounds activate TRPA1 ion channels through covalent modification of cysteines. Nature 445:541-545.

Mironov SL, Lux HD (1991) Cytoplasmic alkalinization increases highthreshold calcium current in chick dorsal root ganglion neurones. Pflugers Arch 419:138-143. 
Padanilam BJ, Lu T, Hoshi T, Padanilam BA, Shibata EF, Lee HC (2002) Molecular determinants of intracellular $\mathrm{pH}$ modulation of human Kv1.4 N-type inactivation. Mol Pharmacol 62:127-134.

Pidoplichko VI (1992) Ammonia and proton gated channel populations in trigeminal ganglion neurons. Gen Physiol Biophys 11:39-48.

Salazar H, Llorente I, Jara-Oseguera A, García-Villegas R, Munari M, Gordon SE, Islas LD, Rosenbaum T (2008) A single N-terminal cysteine in TRPV1 determines activation by pungent compounds from onion and garlic. Nat Neurosci 11:255-261.

Story GM, Peier AM, Reeve AJ, Eid SR, Mosbacher J, Hricik TR, Earley TJ, Hergarden AC, Andersson DA, Hwang SW, McIntyre P, Jegla T, Bevan S, Patapoutian A (2003) ANKTM1, a TRP-like channel expressed in nociceptive neurons, is activated by cold temperatures. Cell 112:819-829.

Tominaga M, Caterina MJ, Malmberg AB, Rosen TA, Gilbert H, Skinner K, Raumann BE, Basbaum AI, Julius D (1998) The cloned capsaicin receptor integrates multiple pain-producing stimuli. Neuron 21:531-543.
Valenzano KJ, Grant ER, Wu G, Hachicha M, Schmid L, Tafesse L, Sun Q, Rotshteyn Y, Francis J, Limberis J, Malik S, Whittemore ER, Hodges D (2003) $\mathrm{N}$-(4-tertiarybutylphenyl)-4-(3-chloropyridin-2-yl)tetrahydropyrazine $-1(2 \mathrm{H})$-carbox-amide (BCTC), a novel, orally effective vanilloid receptor 1 antagonist with analgesic properties: I. in vitro characterization and pharmacokinetic properties. J Pharmacol Exp Ther 306:377-386.

Xiao B, Dubin AE, Bursulaya B, Viswanath V, Jegla TJ, Patapoutian A (2008) Identification of transmembrane domain 5 as a critical molecular determinant of menthol sensitivity in mammalian TRPA1 channels. J Neurosci 28:9640-9651.

Yodozawa S, Speake T, Elliott A (1997) Intracellular alkalinization mobilizes calcium from agonist-sensitive pools in rat lacrimal acinar cells. J Physiol 499:601-611.

Zong X, Stieber J, Ludwig A, Hofmann F, Biel M (2001) A single histidine residue determines the $\mathrm{pH}$ sensitivity of the pacemaker channel HCN2. J Biol Chem 276:6313-6319. 